\title{
Programa Universidade para Todos (PROUNI): quem ganha o quê, como e quando?*
}

\author{
Márcio Rodrigo de Araújo Souza** \\ Monique Menezes***
}

\section{Resumo}

O tema central deste artigo é o Programa Universidade para Todos (PROUNI), criado pelo governo federal em 2004 visando à expansão do acesso à educação superior no país. Analisamos a política, tomando como referência a proposta de definição criada por Lasswell (1936). Buscamos identificar quais atores ganharam o quê, quando e como, a partir do processo político desenvolvido durante a formulação do programa. A hipótese de trabalho foi construída a partir de Pinto (2004), o qual sugeriu que as instituições privadas de educação superior passariam a pressionar o governo em busca de recursos para superar a situação diagnosticada no início da última década, quando as taxas de ociosidade de vagas andavam acima de 740 mil. Analisamos os principais mecanismos do PROUNI: os critérios de acesso, os tipos de bolsas, as exigências qualitativas do ensino e os mecanismos de controle institucionais criados para acompanhar a implementação da política. Em razão disso, concluímos que os atores sociais privatistas tiveram êxito em influenciar as decisões governamentais em prol das expectativas do mercado, o que acarreta na ratificação da tese de Downs (1999), para o qual os atores que têm sua renda afetada por uma política pública estarão sempre mais bem informados e dispostos a participar das discussões que envolvem sua definição.

Palavras-chave: PROUNI; educação superior; política pública.

* Este artigo é derivado da dissertação de mestrado defendida em 2013 pelo primeiro autor sob a orientação da segunda autora no âmbito do Programa de Pós-graduação em Ciência Política da Universidade Federal do Piauí, cujo título é: A Política de Expansão da Educação Superior no Brasil: avaliação e análise do Programa Universidade para Todos.

** Mestre em Ciência Política pela Universidade Federal do Piauí - UFPI. Auditor Governamental na Controladoria-Geral do Estado do Piauí. Membro do Núcleo de Estudos sobre Instituições e Políticas Públicas - NIPP. Email: marciorasouza@gmail.com

*** Doutora em Ciência Política pelo Instituto Universitário de Pesquisa do Rio de Janeiro - IUPERJ. Professora Adjunta do Programa de Mestrado da UFPI e Coordenadora no Núcleo de Estudos sobre Instituições e Políticas Públicas - NIPP. Email: moniquemenezes@gmail.com 


\section{Introdução}

Nas últimas décadas o Brasil vem apresentando mudanças consideráveis na área da educação. A partir dos anos 1990, houve uma expansão significativa de acesso aos ensinos fundamental e médio e, posteriormente, uma massa de jovens almejando cursar o ensino superior. Neste sentido, caberia ao governo federal elaborar e implementar uma política pública nacional de expansão de vagas na educação superior. Paralelo a esse processo, as faculdades e universidades privadas também se prepararam para absorver estes jovens recém -formados. Este artigo trata da política adotada no Brasil para a inclusão desses jovens, mais especificamente do Programa Universidade para Todos (PROUNI).

O ponto de partida é a famosa questão formulada por Lasswell (1936) que até hoje tem sido um paradigma para a definição da política: "Politics: who gets what, when, how?" (Política: quem ganha o quê, quando, como?). Uma política pública não nasce espontaneamente, como num passe de mágica, apenas em decorrência da ideia concebida por um gestor público. Elas são formuladas em meio a um complexo jogo político, no qual diversos atores buscam influenciar a decisão governamental em favor dos seus interesses. Nesse contexto, o principal objetivo deste artigo é compreender o jogo político desenvolvido em torno do processo de criação da política pública, identificando quais atores foram exitosos em influenciar a decisão governamental, o que ganharam com isso, como ganharam e a partir de quando. De modo complementar, também realizaremos uma análise da eficácia dos controles institucionais estabelecidos sobre o PROUNI.

Para alcançarmos os objetivos deste estudo propomos a utilização do método de pesquisa qualitativa, beneficiando nos da técnica de análise de discurso. Este tipo de técnica busca o conhecimento de uma realidade por detrás do texto, por meio de um estudo crítico do conteúdo de texto. As principais características desta metodologia são:

1) Posicionamento crítico em relação ao conhecimento dado;

2) A abordagem de que o conhecimento é socialmente construído;

3) A perspectiva de que as maneiras de compreensão do mundo são historicamente e socialmente relativas (GILL, 2000). 
A partir deste enquadramento metodológico, analisamos a trajetória política do programa tomando como referência os três documentos fundamentais que representaram seus estágios inicial, intermediário e final. Trata-se, respectivamente do Projeto de Lei (PL) n. 3.582/2004 (BRASIL, 2004a), da Medida Provisória (MP) n. 213/2004 (BRASIL, 2004b) e da Lei Ordinária Federal (LOF) n. 11.096/2005 (BRASIL, 2005a). A análise comparativa desses documentos delineia um caminho para responder quem ganhou o quê, como e quando conseguiu êxito com a definição da política pública. Além desses documentos, utilizamos também o relatório de auditoria operacional do Tribunal de Contas da União (BRASIL, 2009) como referência nas análises sobre a eficácia dos controles institucionais estabelecidos sobre o programa. Por fim, coletamos informações do Instituto Nacional de Estudos e Pesquisas Educacionais para a elaboração de análises descritivas do Ensino Superior no Brasil. ${ }^{1}$

Tomamos como hipótese de trabalho a afirmação de Pinto (2004), segundo a qual a capacidade ociosa das instituições de ensino superior privadas (IESP), constatada no início da última década, as obrigaria a buscar influenciar políticas públicas capazes de preencher suas vagas ociosas e evitar a falência de muitas instituições privadas. De um modo geral, os atores sociais buscam influenciar o processo de formulação da política pública por meio de lobby junto aos atores governamentais. No Brasil, porém, dado que essa prática não é regulamentada, os grupos de interesse trabalham ocultamente nos bastidores da política, de modo a influenciar as decisões de acordo com seus interesses. Esse argumento é corroborado pelo relatório do Banco Interamericano de Desenvolvimento (BID) sobre o comportamento dos atores no processo de formulação das políticas públicas (BID, 2007).

Além desta introdução, o texto é composto de cinco seções. Na primeira, apresentamos uma definição conceitual de política pública, de modo a especificar a classificação adotada ao longo do trabalho. Na segunda, fazemos uma contextualização teórico-ideológica em face do processo de criação do PROUNI. Na terceira, traçamos uma breve síntese explicativa a respeito do programa, demonstrando seu funcionamento básico. A quarta seção, na qual analisamos o processo de formulação da política, está dividida em três partes: uma para discutir a questão da quantidade e dos tipos de bolsas de estudo, outra

1 Destacamos ainda que o modelo de análise completo foi desenvolvido em Souza (2013), partindo do pressuposto de que os atores que têm interesse na política pública buscam influenciar a decisão governamental em prol dos seus objetivos e que aqueles que têm seu faturamento impactado por ela lutam com mais afinco nessa missão. 
para debater o tema da necessidade de investir na qualidade da educação superior, e mais uma para demonstrar como ficou o aparato institucional de controle da execução do programa em face do lobby dos atores privatistas. E, finalmente, na última seção concluímos que os atores sociais privatistas lograram êxito em influenciar a decisão governamental no processo de formulação do programa, tornando-o mais vantajoso aos interesses das IESP, embora isso não tenha implicado a derrocada total dos interesses populares.

\section{Definição de política pública}

Tem sido uma tarefa árdua estabelecer uma definição unânime em torno do conceito de política pública. Vários autores vêm enfrentando esse desafio sob as mais variadas perspectivas: política, social, econômica, administrativa. Contudo, os principais achados literários apontam no sentido de que sua definição está interligada com as respostas dadas a alguns questionamentos fundamentais.

Secchi (2010, p. 2) sustenta que essas questões básicas são:

1. Políticas públicas são elaboradas exclusivamente por atores estatais? $\mathrm{Ou}$ também por atores não estatais?

2. Políticas públicas também se referem à omissão, ou à negligência?

3. Apenas diretrizes estruturantes (de nível estratégico) são políticas públicas? $\mathrm{Ou}$ as diretrizes mais operacionais também podem ser consideradas políticas públicas?

Há muitas maneiras de responder a esses problemas. A respeito da responsabilidade formal pelas políticas públicas, há autores, a exemplo de Secchi (2010) e Heidemann (2009), que opinam no sentido de que o caráter público da política não representa necessariamente apenas a esfera estatal, de modo que atores não estatais poderiam criar e implementar políticas públicas. De maneira oposta, outra corrente defende que o caráter público da política implica a ação coercitiva do Estado em executar determinadas ações, de modo que isso afastaria do rol dos responsáveis os atores não estatais, em cuja perspectiva estão Rua (2009) e Souza (2007). Nós entendemos que os atores privados participam efetivamente de todo o processo de formulação e implementação de diversas políticas públicas e também promovem ações sociais de interesse público, embora a política pública em si seja caracterizada pela presença governamental. As definições usadas por alguns autores clássicos citados por Souza (2007), tais como: Lynn (1980), Dye (1984), 
Peters (1986) e Mead (1995), todas elas estabelecem o governo como ponto central, do qual se originam as decisões, as ações ou as omissões que caracterizam as políticas públicas. Rua (2009) compartilha do mesmo entendimento, pois, segundo a autora, mesmo que entidades privadas participem da sua formulação ou implementação sempre estarão vinculadas a uma decisão governamental.

É natural que as atenções sejam majoritariamente direcionadas para as ações tomadas quando se pensa em políticas desenvolvidas por determinado governo, pois isso evidencia a atitude e os esforços dispensados na consecução da política. No entanto, de acordo com Souza (2006), desde a década de 1960 há estudos que comprovam que não fazer nada em relação a um problema, também é uma forma de política pública. Nessa linha de raciocínio, as políticas públicas são as ações desenvolvidas pelo Estado e também as omissões decididas conscientemente pelos agentes governamentais. No entanto, a omissão só pode ser atendida como uma política pública se ela estiver relacionada com um problema público, explícito, colocado na agenda política. Em face dos problemas latentes, restritos, não consideramos a omissão como uma política pública, porque isso levaria à indefinição do conceito.

Finalmente, a terceira questão apresentada acima tem implicação direta sobre o viés conceitual tratado nesse artigo, pois pretende responder se a política pública deve ser considerada apenas na dimensão estratégica, ou se também pode ser compreendida no âmbito das decisões operacionais. Tomamos como ponto de partida novamente o problema público. Caso a decisão seja adotada, no sentido de solucioná-lo, não importa em que dimensão ela se encontra formalmente. Em tese, tanto as diretrizes estratégicas, quando os procedimentos operacionais são importantes para criar uma política pública efetiva, de modo que um conjunto amplo de atores, instituições e recursos são interligados visando alcançar a finalidade da política. Às vezes uma questão tratada pelo governo no nível operacional por ter importância preponderante para a sociedade e vice-versa. No caso específico do PROUNI, ele foi constituído em forma de programa para tratar de um problema educacional, mas dada a sua dimensão, importância, relevância e materialidade, pode ser tratado como uma política pública que visa à promoção do acesso ao ensino superior.

Portanto, políticas públicas podem ser compreendidas como ações ou omissões adotadas por um governo que demonstra sua atitude perante os problemas públicos que fazem parte da agenda política. 


\section{Um pano de fundo ideológico}

Entre o final da década de noventa e o início do século XXI a comunidade acadêmica, os atores sociais, atores governamentais e atores sistêmicos travavam um intenso debate sobre o caráter intrínseco da educação superior, no sentido de concebê-la como um bem público, cujos retornos eram percebidos pela sociedade, ou como um bem individual/privado, cujos benefícios alcançariam as pessoas que investiam em sua própria formação. No rol desses debates, podese citar: Gomes (2003); Dias (2003); Mancebo (2004); Dias Sobrinho (2004); Pires (2004); Corbucci (2004); Silva Jr. e Sguissardi (2005). Mas, no fundo, o que se buscava estabelecer era: o Estado deve financiar a educação superior, ou cada indivíduo é responsável por investir em sua própria formação? Aceitando que, sem prejuízo dos investimentos privados, o Estado pode financiar a formação universitária dos seus cidadãos, deve-se estabelecer outro conceito: os recursos públicos podem ser aplicados nas instituições privadas de ensino, ou o dinheiro do erário deve ser usado apenas nas instituições públicas?

Os atores envolvidos no processo de formulação da política nacional de educação não discordavam que a forma de financiamento traria impacto significativo na expansão do acesso ao ensino superior no país. No entanto, quando o debate pendeu para o lado da forma desse financiamento o cenário mudou, pois uns defenderam que os recursos orçamentários deveriam ser substancialmente ampliados para esse fim (atores publicistas ${ }^{2}$ ), enquanto outros argumentaram que o mercado é que deveria ser o responsável por essa ação (atores privatistas ${ }^{3}$ ). Entre financiamento totalmente público e financiamento totalmente privado havia algumas outras posições intermediárias em debate.

Segundo Carvalho (2011), havia duas posições opostas: em defesa da educação superior como bem público ficaram a União Nacional dos Estudantes (UNE), a Associação Nacional dos Dirigentes das Instituições Federais de Ensino Superior (ANDIFES) e a Associação Nacional dos Docentes em Educação Superior (ANDES); advogando em favor de que a educação seria um bem privado estavam o Banco Internacional para Reconstrução e Desenvolvimento (BIRD)

2 Denominamos aqui atores publicistas aqueles que no cenário de formação do PROUNI defenderam que o estado não deveria aplicar recursos do erário na rede privada de ensino, investindo todos os recursos orçamentários em prol da educação pública, gratuita e de qualidade. Ex. ANDES.

3 Conceituamos como atores privatistas todos aqueles que defendiam a tese contrária, de acordo com a qual o estado deveria, sim, investir recursos públicos no ensino superior privado, de forma direta ou indireta, como se deu no caso do PROUNI. Ex. ABMES. 
e a Associação Brasileira de Mantenedoras do Ensino Superior (ABMES). Mas também existia um grupo de atores que se expressavam no sentido de que esse tipo de educação poderia ser financiada tanto pelo Estado, quando pelo mercado (leia-se, pelos próprios indivíduos interessados): Organização das Nações Unidas para a Educação, a Ciência e a Cultura (UNESCO), Associação Brasileira de Comunidades Comunitárias (ABRUC) e Conselho dos Reitores das Universidades Brasileiras (CRUB).

A criação do PROUNI se deu nesse contexto de fortes debates ideológicos em torno do papel do Estado na política nacional de educação superior. A expectativa era que, com a eleição do primeiro governo considerado de esquerda da história do país, essa política fosse influenciada pelas teses em favor do caráter público do ensino universitário. O slogan usado pelos diversos atores publicistas já apontava nessa direção: "universidade pública, gratuita e de qualidade".

O que se viu foi, toda via ou não obstante a frustração dessa expectativa, dado que o PROUNI foi concebido de acordo com a tese de que o Estado pode financiar a formação superior de sua população e, para isso, pode aplicar recursos tanto nas instituições públicas, quanto nas entidades privadas. A lógica de funcionamento do programa explica essa opção, pois o governo federal deixa de arrecadar receitas tributárias em troca de vagas para estudantes de baixa renda na rede privada de educação superior.

\section{0 que é o PROUNI?}

"O processo de formulação de políticas é um jogo dinâmico entre atores que interagem naquilo que pode ser chamado de arenas" (BID, 2007). Nessa arte são envolvidos tanto atores formais (partidos políticos, parlamentares, executivos, burocratas), como atores informais (movimentos sociais, mídia, grupos de interesse). As arenas, da mesma forma, podem ser formais (parlamento, gabinetes executivos) ou informais (ruas, redes sociais). Souza (2013) analisou as mudanças promovidas nas regras do PROUNI ao longo de sua tramitação entre o Palácio do Planalto e o Congresso Nacional, e, comparando as alterações realizadas nessas duas arenas a partir dos documentos legais PL n. 3.582/2004 (BRASIL, 2004), MP n. 213/2004 (BRASIL, 2004b) e LOF n. 11.096/2005 (BRASIL, 2005a), concluiu que as transformações mais importantes aconteceram entre a retirada do PL do 
Congresso e a elaboração da MP pelo Planalto. Em razão disso, tornouse difícil identificar expressamente a influência de cada ator no processo de mudança, como poderia ser feito literalmente em caso de modificação a partir de emendas parlamentares, por exemplo. Contudo, por dedução aferida a partir dos interesses implícitos de cada grupo de atores envolvido com a política e corroborados pela tese de outros autores, a exemplo de BID (2007), Downs (1999), Carvalho (2011), Carvalho (2006) e Catani, Hey e Gilioli (2006), elaboramos um quadro de pontos essenciais que seriam focados pelos grupos interessados e suas respectivas predisposições para influenciar as mudanças.

Usamos como fundamentação teórica desse modelo a tese de Downs (1999), de acordo com a qual para a maioria da população é irracional obter informações precisas acerca das ações do governo, dado que não percebem benefício decorrente do processo de manter-se informado. Porém, para um pequeno grupo de atores, os que têm interesse econômico nas decisões governamentais, é imprescindível adquirir o máximo de informações possível para buscar influenciar a política. O comportamento dos atores sociais que defendiam os interesses das IESP, os quais estiveram sempre bem informados e atuaram fortemente em todas as arenas de discussão da política, é perfeitamente explicado pela tese do autor, dado que "Apenas alguns cidadãos podem racionalmente tentar influenciar a formulação de cada política governamental; para a maioria, é irracional saber qualquer coisa sobre a formulação até mesmo daquelas políticas que os afetam" (DOWNS, 1999, p. 258).

$\mathrm{Na}$ Quadro 1 abaixo apresentamos uma síntese do modelo utilizado para interpretar o comportamento dos atores no processo de concepção do PROUNI. A lógica é que os estudantes receberiam maiores benefícios, na medida em que a quantidade de bolsas fosse ampliada, que os investimentos das entidades educacionais fossem maiores e que os controles institucionais sobre elas fossem mais rigorosos. Já para as IESP interessaria que os benefícios fiscais fossem maiores, e que as exigências citadas acima fossem menores. Trata-se de um modelo que tem as características, finalidades e restrições do gênero, mas ressaltamos que as análises foram feitas tomando como referência o conjunto das instituições, sem direcionar atenção especial a nenhuma delas. 


\section{Quadro 1. Interesse dos atores em torno do PROUNI}

\begin{tabular}{|l|l|l|}
\hline $\begin{array}{l}\text { Interesse dos } \\
\text { estudantes }\end{array}$ & Formação da política pública & Interesse das IESP \\
\hline+ & Quantidade das vagas gratuitas & - \\
\hline+ & Exigibilidade dos controles institucionais & - \\
\hline+ & $\begin{array}{l}\text { Exigência de investimentos em prol do } \\
\text { serviço oferecido (qualidade do ensino) }\end{array}$ & - \\
\hline- & Benefícios tributários concedidos & + \\
\hline
\end{tabular}

Fonte: Os autores adaptado de SOUZA (2013).

O PROUNI faz parte da política nacional de educação superior, na qual tem a função de promover a expansão do acesso da população de baixa renda a esse nível de ensino. Ele está em vigor desde o segundo semestre de 2004. Sua lógica de funcionamento consiste em oferecimento de bolsas de estudo gratuitas pelas IESP para as pessoas enquadradas nos critérios de seleção, em contrapartida da isenção tributária concedida pelo governo federal às empresas. ALOF $n^{\circ}$. 10.096/2005 (BRASIL, 2005a), fruto da conversão da MP n ${ }^{\circ}$. 213/2004 (BRASIL, 2004b) e o Decreto federal nº. 5.493/2005 (BRASIL, 2005b) são as principais referências documentais desta seção.

O meio de acesso ao programa é o Exame Nacional do Ensino Médio (ENEM). As pessoas que pretendem obter bolsas precisam somar mais de $45 \%$ de acertos nas provas objetivas e não "zerar" a prova discursiva do ENEM. Os candidatos que tiverem esse desempenho e se enquadrarem nos requisitos do programa passam para a segunda etapa que consiste na solicitação de matrícula em uma das IESP participantes.

Há três tipos de bolsas de estudo: (1) a bolsa integral, cujo aluno contemplado recebe $100 \%$ de isenção da mensalidade; (2) a bolsa parcial de 50\%, por meio da qual o aluno fica encarregado de pagar metade da mensalidade; e (3) a bolsa parcial de $25 \%$, a qual obriga o aluno a custear $75 \%$ do valor da mensalidade com recursos próprios. $\mathrm{O}$ Ministério da Educação e Cultura (MEC) tem evitado permitir que as IESP ofereçam as bolsas parciais de $25 \%$, embora elas tenham sido instituídas por lei.

Para concorrer às bolsas, os candidatos devem comprovar alguns requisitos: (1) ter renda familiar mensal per capita menor que três salários mínimos; (2) não ser graduado ou estar matriculado em instituição pública de ensino superior; (3) ter cursado a educação básica integralmente na rede pública de ensino, exceto no caso 
da pessoa que recebeu bolsa integral para frequentar estabelecimento privado; (4) ser portador de necessidade especial; (5) ser professor da rede pública de educação básica e, não possuindo formação superior na área de atuação, queira formar-se nas áreas de licenciatura, pedagogia ou normal superior. Neste último caso os critérios anteriores não serão observados. Destaca-se que as pessoas com renda familiar per capita mensal inferior a um salário mínimo e meio podem pleitear as bolsas integrais. Quem possui renda familiar mensal per capita entre um e meio e três salários mínimos está apto a conseguir uma bolsa parcial.

As IESP são responsáveis por disponibilizar as vagas destinadas ao PROUNI para as pessoas que obtiveram nota satisfatória no ENEM. Os candidatos procuram essas instituições, preenchem o formulário socioeconômico, que deve ser usado para averiguar se o aluno está dentro do público-alvo do programa e aguardam a publicação do resultado, que deve seguir a ordem decrescente de pontuação dos candidatos até preencher as vagas disponibilizadas.

As IESP podem ocupar 4,5\% $(1 \div 22)$ das suas vagas com bolsistas integrais do PROUNI, desde que ofereçam bolsas parciais até alcançar índice de 8,5\% de gratuidades, em relação ao seu faturamento com cursos de graduação. Alternativamente, elas podem oferecer $9,3 \%(1 \div 10,7)$ de bolsas integrais em relação aos alunos matriculados pagantes. As entidades beneficentes de assistência social que atuem no ensino superior seguem uma regra diferenciada, pois devem ocupar com bolsistas integrais $11 \%(1 \div 9)$ das vagas relativamente aos alunos matriculados pagantes e, de forma complementar, devem oferecer bolsas parciais até alcançar o índice de $20 \%$ de gratuidades em relação ao seu faturamento bruto. Elas aderem ao PROUNI por meio de um termo de adesão pactuado junto ao MEC com vigência de 10 anos, prorrogáveis.

Em troca das bolsas gratuitas ofertadas, as IESP passam a gozar de isenções tributárias, de acordo com sua categoria institucional. Os tributos envolvidos na negociação das bolsas de estudos são: Imposto de Renda das Pessoas Jurídicas (IRPJ); Contribuição Social sobre o Lucro Líquido (CSLL); Contribuição Social para Financiamento da Seguridade Social (COFINS); e Contribuição para o Programa de Integração Social (PIS).

Todas as IESP receberam isenção total de todos esses tributos, embora isso tenha causado efeitos diferentes em cada tipo institucional, dado que as entidades beneficentes de assistência social que atuam no ensino superior só 
contribuíam para o PIS com 1\% sobre a folha de salários, enquanto as demais IESP sem fins lucrativos pagavam apenas PIS (1\% sobra a folha de salários) e COFINS ( $3 \%$ sobre o faturamento). Já as IESP lucrativas pagavam antes do PROUNI 25\% de IRPJ e 9\% de CSLL sobre o lucro líquido, mais 3\% de COFINS e $0,65 \%$ de PIS sobre o faturamento.

\section{0 jogo político: uma vitória dos atores organizados}

A formulação do PROUNI teve uma trajetória legislativa marcada por consideráveis reviravoltas, manobras do Poder Executivo e forte influência de lobby ao longo do processo de discussão do texto final da lei no Congresso Nacional $(\mathrm{CN})$. Autores como Carvalho (2006), Neves, Raizer e Fachinetto (2007) e Catani, Hey e Gilioli (2006) afirmam que, no processo de formulação da política pública em discussão, o governo cedeu ao lobby das instituições mantenedoras de ensino superior em prejuízo de reivindicações das camadas populares. De fato, quase todas as mudanças realizadas no texto legal, desde o PL n ${ }^{\circ}$. 3.582/2004 (BRASIL, 2004a), passando pela MP $\mathrm{n}^{\circ}$. 213/2004 (BRASIL, 2004b) até chegar a LOF no. 11.086/2005 (BRASIL, 2005a), foram no sentido de restringir os direitos estudantis e aumentar as vantagens das IESP.

A primeira iniciativa do governo para criação do PROUNI foi submetida ao CN com pedido de urgência constitucional. Em apenas cinco dias, entre 03 de junho de 2004 e 07 de junho de 2004, o texto do PL recebeu 292 emendas, oriundas de 20 parlamentares diferentes. Ato contínuo, o governo retirou o pedido de urgência constitucional para votação do projeto, alegando que o mesmo estaria dificultando a aprovação da lei orçamentária para o exercício financeiro de 2005. Porém, o argumento governamental não possui fundamento técnico, dado que a regra constitucional determina que as matérias que possuam prazo constitucional para aprovação (como é o caso do orçamento) não são sobrestadas pelo trancamento da pauta causado pela expiração do prazo de votação do projeto com pedido de urgência previsto no $\S 1^{\circ}$ do art. 64 da Constituição Federal (CF). Nesse sentido, a retirada do pedido de urgência constitucional serviu como álibi do governo para retirar a formulação da política da arena congressual e trazê-la para o âmbito do Planalto. Tanto assim que, alguns dias depois da retirada do projeto de lei, o governo publicou a medida provisória que institui o PROUNI de forma unilateral, impondo sérias restrições aos estudantes, conforme será demonstrado em seguida ${ }^{4}$ (SOUZA, 2013).

4 Deve-se destacar que o envio de Projetos de Lei com pedido de urgência e sua retirada em seguida é uma manobra constante do Poder Executivo, que tem a finalidade de observar o teor das emendas dos parlamentares. O objetivo é verificar a reação do Congresso e a direção das emendas. 


\subsection{Tipos e quantidades de bolsas}

O ponto central da política pública em discussão é, sem dúvida, a quantidade de bolsas que cada IESP deve ofertar gratuitamente, em relação ao número total de estudantes pagantes. O PL n ${ }^{\circ}$. 3.582/2004 (BRASIL, 2004a) estabelecia uma regra simples: para cada nove alunos matriculados pagantes a IESP deveria ofertar uma bolsa integral gratuita. Não obstante, o texto original contido no PL foi substancialmente alterado pela MP n. 213/2004 (BRASIL, 2004b) para a destinação de bolsas aos estudantes de baixa renda, criando uma relação de possibilidades de combinações.

A primeira modificação efetuada no formato da política passou a estabelecer que a metade das bolsas integrais poderia ser convertida em meias-bolsas (1/2), na razão de duas metades para cada bolsa integral. Em seguida, criou-se uma nova regra, a partir da qual as IESP poderiam ofertar apenas uma bolsa integral para cada 19 alunos pagantes matriculados, desde que as IESP ofertassem tantas meias-bolsas quantas fossem necessárias para acumular 10\% de bolsas em relação ao seu faturamento com cursos de graduação.

A regra final da política para a distribuição de bolsas estabelecida pela LOF $\mathrm{n}^{\circ}$. 11.096/2005 (BRASIL, 2005a) ficou ainda mais complexa e desfavorável aos estudantes, pois passou a permitir que as IESP pudessem ofertar uma bolsa integral para cada 10,7 alunos pagantes matriculados. De forma alternativa, a instituição poderia mudar o critério, ofertando uma bolsa integral para cada 22 alunos pagantes e distribuir tantas bolsas parciais quantas fossem necessárias para atingir um percentual de bolsas de $8,5 \%$ do seu faturamento com cursos de graduação.

Em síntese, o total das bolsas de estudo passou de $10 \%$ do faturamento com graduação para $8,5 \%$ desse faturamento. Adicionalmente, criou-se a figura da meia-bolsa (pagamento de $50 \%$ do valor da mensalidade) e da bolsa parcial (pagamento de $75 \%$ do valor da mensalidade). Assim, estabeleceuse a possibilidade da própria IESP fazer ajustes para distribuir menos bolsas integrais e compensar com oferecimento de bolsas parciais de $1 / 2$ ou 1/4.

Originalmente, a regra era bastante clara: havia apenas a bolsa integral e deveria ser disponibilizada uma bolsa para cada nove alunos pagantes matriculados. A partir do momento que se alterou essa regra, criando uma gama de possibilidades, abriram-se brechas para que IESP mal-intencionadas pudessem jogar utilizar os 
números, disponibilizando uma quantidade de vagas menor que o exigido pela lei. De forma paralela, o texto legal excluiu a exigência de que a proporção de vagas fosse mantida em todos os cursos e unidades administrativas das instituições. Essa manobra também acarreta um sensível impacto negativo nas regras do PROUNI, pois, na prática, o governo passou a permitir que as IESP preenchessem as vagas destinadas ao programa majoritariamente em dois tipos de cursos: os de menor concorrência; e os de menor custo de criação e manutenção.

A regra de uma bolsa integral para cada 22 alunos pagantes cria uma deficiência operacional na política que abre portas para práticas oportunistas das IESP, isso porque são as próprias IESP que informam o número de alunos matriculados e pagantes em cada curso e o valor das respectivas mensalidades. Como esses dados são o ponto de partida para o cálculo das bolsas do programa e o MEC não exerce qualquer controle sobre isso, as IESP podem manipular os números apresendos para ofertar a menor quantidade possível de bolsas. Pela mesma razão, elas podem ainda ofertar mais bolsas em cursos mais baratos e menos concorridos e não ofertar bolsas em cursos mais concorridos e caros (BRASIL, 2009).

Em relação à distribuição das bolsas de estudo por cursos oferecidos pelas IESP, havia no texto inicial do PL no. 3.582/2004 (BRASIL, 2004a) a determinação de que a mesma proporção de bolsas ofertadas na IESP deveria ser mantida em todos seus os cursos e unidades administrativas. Esse era um ponto positivo da política, dado que obrigaria a IESP a ofertar bolsas não só nos cursos "mais baratos" e menos concorridos. Essa exigência as obrigaria a oferecer bolsas em cursos mais concorridos e mais caros (como, por exemplo, os cursos na área da saúde).

No entanto, a partir da edição da MP n. 213/2004 (BRASIL, 2004b) essa regra foi suprimida do PROUNI. O novo texto fixou que as regras de proporcionalidade deveriam ser estabelecidas, doravante, no termo de adesão das IESP ao programa. Essa modificação tornou as regras do programa frouxas porque as IESP não estão mais obrigadas a ofertar as bolsas na mesma proporção em cada curso, unidade administrativa e turno. Desse modo, considerando inclusive a falta de controle do MEC em relação à implementação do programa, podese concluir que as IESP tenderão sempre a restringir o acesso dos estudantes bolsistas aos seus cursos mais concorridos, para os quais há ocupação de todas as vagas, disponibilizando as bolsas nos cursos de menor concorrência, para os quais haja excesso de vagas. $\mathrm{O}$ mesmo raciocínio pode ser aplicado para a 
distribuição das bolsas por turno e por unidade administrativa, ou seja, as IESP tenderão sempre a ofertar as bolsas nos turnos e unidades menos concorridos.

Em face do até aqui exposto, pode-se concluir que os atores sociais privatistas foram exitosos em influenciar a decisão governamental em prol dos seus interesses. Eles conseguiram, principalmente nos gabinetes do Palácio do Planalto (dado que as principais mudanças nas regras do programa ocorrem entre o PL e a MP), mudar as regras do programa, tornando-as mais próximas das expectativas das IESP, as quais apresentavam um ano antes da aprovação da medida mais de 725 mil vagas ociosas em todo o Brasil. Pelas regras aprovadas, essas instituições passariam a oferecer uma quantidade menor de bolsas gratuitas e sem deixar de usufruir de todos os benefícios tributários integralmente.

Os dados apresentados na Tabela 1 seguinte corroboram a hipótese levantada neste trabalho. Observa-se que a cada dois anos houve um aumento significativo na quantidade de vagas não ocupadas. A ociosidade na rede pública foi diminuindo a cada ano, de 1993 até 2003, ao passo que, na rede privada, esses números foram- se expandindo gradativamente. Em 2003, na véspera da criação do PROUNI, havia quase 740 mil vagas não ocupadas nos estabelecimentos de educação superior, das quais $98 \%$ estavam concentradas nas IESP e apenas $2 \%$ nas instituições públicas (federais, estaduais e municipais).

Tabela 1. Crescimento da ociosidade de vagas na educação superior 1993-2003

\begin{tabular}{l|l|l|l|l|l|l}
\hline Ano & \multicolumn{1}{l}{ Total } & \multicolumn{1}{l}{$\Delta \%$} & \multicolumn{1}{l}{ Pública } & \multicolumn{1}{l}{$\Delta \%$} & \multicolumn{1}{l}{ Privada } & \multicolumn{1}{l}{$\Delta \%$} \\
\hline 1993 & 108.877 & - & 17.938 & - & 90.939 & - \\
\hline 1994 & 110.895 & $1,9 \%$ & 17.667 & $-1,5 \%$ & 93.228 & $2,5 \%$ \\
\hline 1995 & 99.978 & $-9,8 \%$ & 20.133 & $14,0 \%$ & 79.845 & $-14,36 \%$ \\
\hline 1996 & 120.394 & $20,4 \%$ & 17.019 & $-15,5 \%$ & 103.375 & $29,47 \%$ \\
\hline 1997 & 125.298 & $4,1 \%$ & 11.962 & $-29,7 \%$ & 113.336 & $9,64 \%$ \\
\hline 1998 & 152.566 & $21,8 \%$ & 17.876 & $49,4 \%$ & 134.690 & $18,84 \%$ \\
\hline 1999 & 181.521 & $19,0 \%$ & 10.739 & $-39,9 \%$ & 170.782 & $26,80 \%$ \\
\hline 2000 & 318.730 & $75,6 \%$ & 12.549 & $16,9 \%$ & 306.181 & $79,28 \%$ \\
\hline 2001 & 371.802 & $16,7 \%$ & 11.877 & $-5,4 \%$ & 359.925 & $17,55 \%$ \\
\hline 2002 & 567.947 & $52,8 \%$ & 14.863 & $25,1 \%$ & 553.084 & $53,67 \%$ \\
\hline 2003 & 739.779 & $30,3 \%$ & 14.132 & $-4,9 \%$ & 725.647 & $31,20 \%$ \\
\hline
\end{tabular}

Fonte: Os autores (2014). 


\subsection{Investimento na qualidade da educação}

$\mathrm{O}$ viés da qualidade do ensino superior tem sido amplamente discutido no Brasil, mesmo antes da implementação da políticas públicas de oferecimento de vantagens tributárias para as IESP em troca de bolsas de estudos para estudantes de média e baixa renda. A opinião dos especialistas tem sido anunciada sempre na direção de que o ensino superior no Brasil não tem avançado em termos qualitativos, apesar da expansão quantitativa observada desde a reforma universitária de 1968 (PINTO, 2004).

De modo geral, o Brasil tem deficiências consideráveis no sistema de ensino superior, dados apresentados por Previdelli (2012) demonstram que o país ocupa da $53^{\circ}$ posição em um rol de 65 países quando o assunto é qualidade da educação superior. Mesmo assim, de acordo com Sguissardi (2006), o sistema público de ensino superior apresenta um nível qualitativo bastante mais elevado que o sistema de educação superior privado. Isso, por um lado, poderia ser notado pelos resultados dos estudantes nos exames avaliativos e, por outro, seria consequência das características das instituições públicas (que, além do ensino, atuam fortemente em pesquisa), ao passo que as IESP trabalham quase exclusivamente na perspectiva da replicação do conhecimento.

Complementarmente, Algebaile (2007) sustenta que a expansão do acesso ao ensino superior acelerada a partir do PROUNI tem sido feita de forma perversa, dado que os cursos que recebem os alunos do programa geralmente apresentam grandes deficiências pedagógicas, resultando em um processo educativo de baixa qualidade. Sob outra ótica, de acordo com a mesma autora, a regra observada na execução da política é o oferecimento de vagas aos estudantes apenas nos cursos mais baratos das IESP, maciçamente naqueles que demandam baixíssimos investimentos por parte das instituições, sem preocupação alguma com a necessidade de formação superior observada no país, o que já foi discutido na seção anterior.

Quando se analisa o processo político em torno da formulação do PROUNI, em relação à qualidade da educação, observa-se que também houve retrocesso. A comparação do formato inicial proposto pelo governo e a estrutura final adotada pela política, após o lobby exercido pelos atores sociais ligados às IESP, aponta claramente para uma degradação das suas exigências qualitativas. A regra inicial estabelecida no PL $n^{\circ}$. 3.582/2004 (BRASIL, 2004a) era que a IESP que tivesse desempenho insuficiente (menor que 3 numa escala que vai até 5) no Sistema 
Nacional de Avaliação da Educação Superior (SINAES) por 2 anos consecutivos ou 3 anos intercalados seria descredenciada e deixaria, via de consequência, de fazer jus a todos os benefícios tributários relacionados com o programa.

A partir da edição da MP $n^{0} .213 / 2004$ (BRASIL, 2004b) o governo modificou o critério, tornando-o mais frouxo, mais permissivo com a falta de qualidade da educação superior nesses estabelecimentos. Na prática, suprimiu-se a regra de desvinculação a partir das avaliações insuficientes intercaladas. Em relação às avaliações insuficientes consecutivas que justificassem o descredenciamento da IESP, o governo ampliou de 2 para 3 avaliações. E o que é pior, suprimiu a desvinculação da instituição e estabeleceu que apenas os cursos com avaliações insuficientes seriam descredenciados. Essa foi outra grande vitória dos atores sociais ligados às IESP, em detrimento da qualidade da educação oferecida pelos estabelecimentos privados de ensino.

Essa mudança na regra é bastante emblemática visto que desobriga a IESP de má qualidade a investir na melhoria do seu padrão de ensino. Evidentemente os cursos não são instituições autônomas, capazes de avançar ou retroceder de forma unilateral, pois fazem parte de um sistema educativo mais amplo, que é a própria instituição. Ora, se esta não deixa de ser beneficiada com as indulgências tributárias do programa em razão da má qualidade do curso X ou Y, dado que ela mantém todos os privilégios com ou sem esse curso, não há nenhum indicativo de que esta instituição irá preocupar-se em investir na melhoria do seu padrão de ensino.

Como discutido em seção anterior, a regra adotada pelo PROUNIé de conceder todos os benefícios fiscais, em suas respectivas totalidades, com base apenas na oferta de vagas das IESP. Essa oferta é feita apenas com base nos dados declarados pelas IESP. Dessa maneira, não há impeditivo para que as IESP façam todos os arranjos necessários para manter seus privilégios sem a correspondente contrapartida em forma de bolsas de estudo aos estudantes, alvos da política pública. Sobretudo não há perspectiva de que estas IESP reduzam seus lucros (e reduzam assim os dividendos dos seus sócios) para investir em qualidade da educação.

Portanto, pode-se concluir que, em relação às exigências legais que poderiam obrigar as IESP a investir mais na melhoria da qualidade dos serviços prestados, houve um inequívoco retrocesso a partir da substituição das regras previstas no PL pelos critérios estabelecidos na MP. Os atores sociais privatistas ganharam uma 
margem de lucro, dado que o governo estabeleceu a isenção completa de todos os tributos envolvidos no programa e minimizou as exigências para investimentos significativos em prol da expansão qualitativa das vagas. Além de minar a desqualificação por avaliações insuficientes, cometeu o equívoco de descredenciar apenas os cursos e, jamais, as instituições. Considerando que os benefícios tributários são auferidos independentemente de haver curso mal avaliado, tornouse inócua a exigência por melhoria de qualidade pelas regras do PROUNI.

\subsection{Controles institucionais}

Nesta seção discutiremos cinco pontos relacionados com critérios estabelecidos para acompanhamento da política pública e sobre requisitos que as IESP deveriam cumprir para fazer jus às vantagens fiscais decorrentes da adesão ao PROUNI: o primeiro, relacionado à exigência de adesão ao FIES como condição necessária para aderir ao PROUNI; o segundo, relacionado com a possibilidade de aplicação de pena pecuniária às IESP que descumprissem as normas do programa; o terceiro, relativo ao acréscimo de bolsas quando constatadas irregularidades quantitativas na distribuição das gratuidades; o quarto, pertinente à possibilidade de descredenciamento da IESP; e o quinto abordando a questão do aparato institucional destinado ao controle da execução da política.

No PL no. 3.582/2004 (BRASIL, 2004a) havia a expressa vinculação entre adesão ao FIES como condição para adesão ao PROUNI. Em tese, o FIES não cria vantagens financeiras para as IESP, sobretudo para aquelas que têm demanda razoável; os principais beneficiários do FIES são os próprios estudantes, pois recebem crédito subsidiado para pagar suas mensalidades no curso e na instituição de sua preferência, desde que essa atenda aos critérios mínimos estabelecidos pela lei. De forma contrária é a lógica do PROUNI, pois este, sim, cria muitas vantagens para as IESP, sobretudo para aquelas com finalidade lucrativa, a partir da isenção tributária demonstrada anteriormente. Por essa razão, inicialmente, o governo pretendia vincular a adesão ao FIES como condição necessária para adesão ao PROUNI. No entanto, dado a atuação dos atores sociais privatistas nos bastidores da política, eles conseguiram já a partir da edição da MP nº. 213/2004 (BRASIL, 2004b) que essa exigência fosse suprimida do formato do programa.

Outro ponto fundamental é a questão em torno das penalidades aplicadas às IESP em caso de descumprimento das regras estabelecidas no termo de adesão 
ao PROUNI. Inicialmente o PL no ${ }^{\circ} .3 .582 / 2004$ (BRASIL, 2004a) previa três penalidades, inclusive em caso de oferecimento efetivo de bolsas em quantidades menores daquelas estipuladas previamente. A primeira penalidade seria a aplicação de multa de até $1 \%$ do faturamento anual da IESP. A segunda seria a imposição de que a IESP acrescentasse a quantidade de bolsas correspondentes àquelas que deixaram de ser efetivamente ofertadas. E por fim, a terceira penalidade seria a desvinculação da IESP do PROUNI.

Mas novamente houve forte atuação dos atores sociais privatistas nos bastidores do Poder Executivo no sentido de restringir ao máximo as possíveis penalidades que pudessem vir a ser aplicadas às IESP. De fato, esses atores conseguiram êxito em suas reivindicações, dado que a partir da MP n. 213/2004 (BRASIL, 2004b) o governo retirou definitivamente a possibilidade de mexer "no bolso" das IESP, excluindo da política a possibilidade de aplicação de multa para as IESP que descumprissem os termos acordados no termo de adesão. A partir da LOF n.11.096/2005 (BRASIL, 2005a) conseguiu-se que em caso de descumprimento do quantitativo de bolsas pela IESP, houvesse, para além do reestabelecimento do número pactuado, um acréscimo de $20 \%$, para compensar as perdas decorrentes da atuação fraudulenta da IESP, ainda assim, isso se aplica apenas para um período de matrícula. Ou seja, mesmo se a IESP ficar vários períodos descumprindo os termos pactuados, a penalização de acréscimo de $20 \%$ na quantidade de bolsas vale só para o período seguinte à descoberta da fraude.

Finalmente, o terceiro ponto crucial relacionado às possíveis penalidades que poderiam ser aplicadas às IESP em caso de descumprimento das normas do PROUNI, tem-se a hipótese de desvinculação da IESP do programa. A regra inicial prevista no PL n. 3.582/2004 (BRASIL, 2004a) era simples: caso a IESP descumprisse as condições pactuadas no termo de adesão ela seria desvinculada pelo MEC do PROUNI. O novo texto publicado pelo governo, que passou a ser usado também na versão final da LOF n. 11.096/2005 (BRASIL, 2005a), mudou essa regra. A partir de então a desvinculação só pode ser solicitada em caso de reincidência, e ainda assim, se a falta for considerada grave, cujo conceito envolve quatro tipos de conduta: reincidência de infração; tratamento discriminatório entre bolsistas e pagantes; falseamento de informações para reduzir a quantidade de bolsas; ou falseamento de informações para aumentar os benefícios fiscais. Em qualquer um dos casos o MEC deve instaurar um procedimento administrativo para apurar indícios de descumprimento das obrigações assumidas pelas IESP no 
termo de adesão. Nesse caso, cabe ao próprio órgão, identificando irregularidades, aplicar as penalidades previstas na lei.

Em relação ao controle fiscal que o governo precisa realizar na execução da política pública, dado que todo seu funcionamento está ancorado na renúncia dos quatro tributos federais (IRPJ, CSLL, CONFINS, PIS) em troca das bolsas de estudo oferecidas, em contrapartida pelas IESP, houve uma evidente degradação do aparato institucional incumbido de acompanhar a arrecadação e a renúncia fiscal do estado com cada uma das entidades participantes do PROUNI.

A proposta inicial exarada no PL $\mathrm{n}^{\circ}$. 3.582/2004 (BRASIL, 2004a) previa que um grupo interministerial formado pela Secretaria da Receita Federal do Brasil (SRFB), Ministério da Previdência Social (MPS) e MEC seria encarregado de controlar todo o montante financeiro arrecadado e renunciado em virtude do PROUNI, inclusive acompanhando as contraprestações da IESP em face dos benefícios fiscais auferidos por elas. A partir a sanção da LOF n. 11.096/2005 (BRASIL, 2005a) esse aparato institucional foi desfeito e passou-se a atribuir todas as atividades ao MEC. Evidentemente que isso representou um prejuízo notório para o controle da eficiência da execução da política.

A questão em análise tem grande repercussão no meio profissional, à época, pois o lobby exercido pela ABMES junto ao governo federal conseguiu fragilizar definitivamente os controles institucionais sobre a execução do programa. Carvalho (2011) demonstra que a mudança promovida pelo governo, afastando as competências dos órgãos de fiscalização e atribuindo toda a responsabilidade por acompanhar a renúncia fiscal e as bolsas efetivamente ofertadas pelo programa, atendeu à reivindicação da ABMES que, em pronunciamento do dia 15 de junho de 2004 havia sugerido que a fiscalização integral do programa deveria ser exclusiva do MEC.

\section{Conclusão}

Ao longo deste artigo, apresentamos alguns pontos em torno dos quais se desenvolveram as principais disputas de interesses no jogo político que contextualizou a formulação do PROUNI. Retomando a questão inicial deste artigo sobre quem ganha o quê, quando, como?" referente a política do PROUNI, observamos que os atores privatistas foram os grandes ganhadores, uma vez que 
conseguiram influenciar a elaboração de um programa amplamente favorável à atuação das instituições de ensino superior. Houve intervenção de atores sociais que buscaram, desenvolvendo lobby junto ao governo ou aos parlamentares, influenciar a definição dos mecanismos de implementação do programa. Os atores sociais ligados às IESP formaram o principal grupo que atuou nesse processo político, algumas vezes de forma explícita, mas, na maioria dos casos, de forma implícita, oculta, atuando nos bastidores do Planalto ou do Congresso.

O resultado das mudanças promovidas na formulação do programa, contrabalançada com os interesses naturais dos diferentes atores sociais, conforme demonstrado na parte inicial do texto, foi suficiente para perceber o quanto os atores privatistas interferiram na definição do modelo do PROUNI, tornando-o, via de consequência, mais próximo das demandas das IESP, do que das necessidades do público-alvo. Pode-se notar isso, de imediato, na análise do ponto central da política: distribuição de bolsas de estudo gratuitas à população de baixa renda pelas IESP em troca de benefícios fiscais concedidos pelo governo federal.

Ao longo deste artigo foi demonstrado que as IESP lograram êxito em modificar todas as regras da política que lhes trariam benefício, reduzindo a quantidade de bolsas, os controles institucionais das exigências de investimentos, sem, contudo, reduzir em nada os benefícios tributários. Nota-se que a única regra importante do programa que não foi alterada foi aquela relativa às isenções fiscais, pois manteve-se a supressão das alíquotas do IRPJ, CSLL, PIS e COFINS.

Essas constatações, contudo, não precisam ser encaradas de forma pessimista, como se o programa tivesse acarretado prejuízos para seu público-alvo. $\mathrm{O}$ PROUNI tem o mérito de estar contribuindo para a ampliação do acesso à educação superior no Brasil, principalmente para a população de renda familiar per capita menor que 3 salários mínimos; porém, ele poderia fazer muito mais, caso as regras originalmente propostas tivessem sido mantidas. Nota-se que a tese de Downs (1999) explica bem o comportamento dos atores no processo de formulação dessa política pública: aqueles que tinham sua renda afetada diretamente pela decisão governamental foram ágeis ao tomar conhecimento do processo e trabalharam intensamente para ter suas demandas atendidas. Já os estudantes, que não usufruíam de quaisquer benefícios, de modo que em qualquer cenário estariam ganhando, não se mobilizaram para tentar pressionar 
o governo. De qualquer forma, trata-se de uma política recente que ainda pode ser analisada em outras perspectivas para além daquelas estudadas neste trabalho. Deste modo, consideramos um campo aberto para futuras pesquisas nos quais podem ser abordados estudos de casos que corroborem ou não com as hipóteses e conclusões aqui apresentadas, bem como a elaboração de análises comparadas com outras políticas do segmento da educação superior.

\section{Referências}

ALGEBAILE, M. E. B. Expansão da Educação Superior: traços de uma inclusão seletiva no cenário educacional brasileiro. In: VIEITEZ, C. G.; BARONE, R. E. M. (Org.). Educação e Políticas Públicas: tópicos para debate. Araraquara, SP: Junqueira\&Martins, 2007.

BID. Banco Interamericano de Desenvolvimento. A política das políticas públicas: progresso econômico e social na América Latina: Relatório 2006. Rio de Janeiro: Elsevier; Washigton: BID, 2007.

BRASIL. Projeto de lei $\mathrm{n}^{\circ} 3.582$, de 18 de maio de 2004. Dispõe sobre a instituição do Programa Universidade para Todos - PROUNI e dá outras providências. 2004a. Disponível em: <http://www.camara.gov.br/proposicoesWeb/ fichadetramitacao?idProposicao=253965. $>$. Acesso em: 22 de janeiro de 2012.

. Medida Provisória n ${ }^{\circ} 213$, de 10 de setembro de 2004. Institui o Programa Universidade para Todos - PROUNI, regula a atuação de entidades beneficentes de assistência social no ensino superior, e dá outras providências. Diário Oficial da União [da] República Federativa do Brasil, Brasília, 13 set. 2004b.

. Lei ${ }^{\circ} 11.096$, de 13 de janeiro de 2005. Institui o Programa Universidade para Todos - PROUNI, regula a atuação de entidades beneficentes de assistência social no ensino superior; altera a Lei $\mathrm{n}^{\mathrm{o}} 10.891$, de 9 de julho de 2004, e dá outras providências. Diário Oficial da União [da] República Federativa do Brasil, Brasília, 14 jan. 2005a.

. Decreto n. 5.493, de 18 de junho de 2005. Regulamenta o disposto na Lei no 11.096, de 13 de janeiro de 2005. Diário Oficial da União [da] República Federativa do Brasil, Brasília, 19 jul. 2005 b. 
BRASIL. Tribunal de Contas da União (TCU). Relatório de auditoria operacional: Programa Universidade para Todos (ProUni) e Fundo de Financiamento ao Estudante do Ensino Superior (FIES). Brasília: TCU, 2009.

CARVALHO, C. H. A. de. A Política Pública para Educação Superior no Brasil (1995-2008): ruptura ou continuidade?. Tese (Doutorado)-Instituto de Economia, Unicamp, Campinas-SP, 2011.

. O PROUNI no governo Lula e o jogo político em torno do acesso ao ensino superior. Educação e Sociedade, Campinas, v. 27, n. 96 - Especial, p. 979-1000, out. 2006.

CATANI, A. M.; HEY, A. P.; GILIOLI, R. de S. P. PROUNI: democratização do acesso às Instituições de Ensino Superior? Educar, Curitiba, n. 28, p. 125$140,2006$.

CORBUCCI, P. R. Financiamento e democratização do acesso à educação superior no Brasil: da deserção do Estado ao projeto de reforma. Educação e Sociedade, Campinas, v. 25, n. 88, p. 677-701, Especial - Out. 2004. Disponível em: <www.scielo.br>. Acesso em: 22 mar. 2012.

DIAS, M. A. R. Comercialização do Ensino Superior: é possível manter a ideia de bem público? Educação e Sociedade, Campinas, v. 24, n. 84, p. 817838, set. 2003. Disponível em: <www.scielo.br>. Acesso em: 22 de mar. de 2012.

DIAS SOBRINHO, J. Avaliação Ética e Política em Função da Educação como Direito Público ou como Mercadoria. Educação e Sociedade, Campinas, v. 25 , n. 88, p. 703-725, Especial - Out. 2004. Disponível em: <www.scielo. br>. Acesso em: 21 de mar. 2012.

DOWNS, A. Uma teoria econômica da democracia. São Paulo: Editora USP, 1999.

GILL, R. Análise de Discurso. In: BAUER, M. W.; GASKELL, G. (Ed.). Pesquisa qualitativa com texto, imagem e som: um manual prático. São Paulo: Editora Vozes, Petrópolis. 2000. 
GOMES, A. M. Estado, Mercado e Educação Superior no Brasil: um modelo anal. Educação e Sociedade, Campinas, v. 24, n. 84, p. 839-872, set. 2003. Disponível em: < www.scielo.br>. Acesso em: 22 de mar. 2012.

HEIDEMANN, F. G. Do sonho do progresso às políticas de desenvolvimento. In: HEIDEMANN, F. G.; SALM, J. F. (Org.). Políticas Públicas e Desenvolvimento: bases epistemológicas e modelos de análise. Brasília, DF: Editora Universidade de Brasília, 2009.

LASSWELL, H. D. Politics: who gets what, when, how? Nova York: MacGraw-Hill, 1936.

MANCEBO, D. Reforma Universitária: reflexões sobre a privatização e a mercantilização do conhecimento. Educação e Sociedade, Campinas, v. 25, n. 88, p. 845-866, Especial - out. 2004. Disponível em: <www.scielo.br>. Acesso em: 22 de mar. 2012.

NEVES, C. E. B.; RAIZER, L.; FACHINETTO, R. F. Acesso, expansão e equidade na educação superior: novos desafios para a política educacional brasileira. Sociologias, Porto Alegre, ano 9, n. 17, p. 346-452, jan-jun. 2007.

PINTO, J. M. de R. O Acesso à Educação Superior no Brasil. Educação e Sociedade, Campinas, v. 25, n. 88, p. 727-756, Especial - out. 2004. Disponível em: <www.scielo.br>. Acesso em: 14 de mar. 2012.

PIRES, V. Ensino Superior e Neoliberalismo no Brasil: um difícil combate. Educação e Sociedade, Campinas, v. 25, n. 86, p. 263-268, abr. 2004. Disponível em: <www.scielo.br>. Acesso em: 14 de mar. 2012.

PREVIDELLI, A. Os gastos do Brasil com educação em relação ao mundo. Exame.com, [S.l.], 2012. Disponível em: <http://exame.abril.com.br/brasil/ noticias/os-gastos-do-brasil-com-educacao-em-relacao-ao-mundo $>$. Acesso em: 12 nov. 12 .

RUA, M. das G. Políticas públicas. Florianópolis: Departamento de Ciências da Administração/UFSC; Brasília, DF: CAPES, UAB, 2009. 
SECCHI, L. Políticas Públicas: conceitos, esquemas de análise, casos práticos. São Paulo: Cengage Learning, 2010.

SGUISSARDI, V. Reforma Universitária no Brasil - 1995-2006: precária trajetória e incerto futuro. Educação e Sociedade, Campinas, v. 27, n. 96 Especial, p. 1021-1056, out. 2006.

SILVA JR., J. dos R.; SGUISSARDI, V. A nova lei de educação superior: fortalecimento do setor público e regulação do privado/mercantil ou continuidade da privatização e mercantilização do público? Revista Brasileira de Educação, n. 29, mai-ago, 2005. Disponível em: <www.scielo.br> . Acesso em: 3 de nov. de 2012.

SOUZA, C. Estado da Arte da Pesquisa em Políticas Públicas. In: HOCHMAN, G.; ARRETCHE, M.; MARQUES, E. (Org.). Politicas Públicas no Brasil. Rio de Janeiro: Editora Fiocruz, 2007. Disponível em: <www. scielo.br>. Acesso em: 12 de mar. 2014.

SOUZA, C. Políticas Públicas: uma revisão da literatura. Sociologias, Porto Alegre, ano 8, n. 16, jul./dez., 2006, p. 20-45. Disponível em: <www.scielo. br>. Acesso em: 12 de mar. 2014.

SOUZA, M. R. de A. A política de expansão da educação superior no Brasil: avaliação e análise do Programa Universidade para Todos. Dissertação (Mestrado)- Centro de Ciências Humanas e Letras, Universidade Federal do Piauí, Teresina-PI, 2013.

\section{University for All Program (PROUNI): who gets what, how and when? \\ Abstract}

The central theme of this article is the Programa Universidade para Todos (PROUNI), created by the federal government in 2004 aiming at the expanding access to higher education in the country. We analyzed the politics with reference to the proposal for the definition created by Lasswell (1936). I try to identify which actors will have won what, when and how, from the political process developed during the formulation of the program. My working hypothesis was 
constructed from Pinto (2004) which has suggested that private institutions of higher education would start to pressure the government for resources to overcome the situation diagnosed early in the last decade, when rates of idleness vacancies were walking up 740,000. I analyzed the main mechanisms PROUNI: access criteria, types of scholarships, the qualitative requirements of education and institutional control mechanisms created to monitor the implementation of policy. As a result, I conclude that social actors privatists were successful in influencing government decisions in favor of market expectations, resulting in the ratification of the thesis Downs (1999), for which the actors have their income affected by a policy public better informed and are always willing to participate in discussions that involve its definition.

Keywords: PROUNI; higher education, public policy.

\section{¿Quiénes son los ganadores? ¿Qué es lo que lo ganan, cómo y cuándo? Un análisis del Prouni Resumen}

El tema central de este artículo es el Programa Universidad para Todos (PROUNI), creado por el gobierno federal en 2004, destinado a ampliar el acceso a la educación superior en Brasil. Analizamos la política bajo la orientación de la definición que Lasswell (1936) propuso. Buscamos identificar dentro de ese contexto quiénes fueron los ganadores, qué es lo que obtuvieron, cuándo lo hicieron y cómo, a partir del proceso político desarrollado durante la formulación del programa. La hipótesis de trabajo se construyó a partir de Pinto (2004), el cual sugiere que las instituciones privadas de educación superior pasarían a presionar al gobierno solicitando recursos para superar la situación diagnosticada a principios de la década pasada, cuando las tasas de ociosidad de plazas eran superior a 740.000. Analizamos los principales mecanismos del PROUNI: criterios de acceso, tipos de becas, los requisitos de calidad de la enseñanza y de los mecanismos de control institucional creados para monitorear la implementación de la política. En consecuencia, se concluye que los actores sociales privatistas lograron influir en las decisiones del gobierno a favor de las expectativas del mercado, dando lugar a la ratificación de la tesis de Downs (1999), para el cual los actores que ven afectados sus ingresos por una política pública están mejor informados y dispuestos a participar en los debates relacionados con su definición.

Palabras clave: PROUNI. Educación superior. Política pública. 